\title{
The pathophysiology does not denote the mechanism
}

\author{
Thomas L. Slovis • Stephen Chapman
}

Received: 31 December 2008 / Accepted: 31 December 2008 / Published online: 23 January 2009

(C) Springer-Verlag 2009

The article "Anatomy and development of the meninges: implications for subdural collections and CSF circulation" by Mack, Squier, and Eastman [1] appears under the rubric "Theoretical considerations." This is a first for Pediatric Radiology and implies the article is both theoretical and controversial.

The material presented is important for all of us to consider in the pathophysiology of subdural collections. What we are most concerned about is subdural hematomas. As radiologists, we must also be concerned with anatomy. The editorial team spent an enormous amount of time with this paper because of our fear of misuse of the information. In the child with subdural hematomas without adequate history to explain their occurrence, nonaccidental trauma (NAT) needs to be the primary consideration. Of course, other medical diseases and bleeding disorders need to be investigated and excluded, but NAT is the correct diagnosis in the vast majority of cases. We believe that the article of Mack et al. reflects this.

It is important to understand that a series of publications (54 and 72 in the article of Mack et al.) and a third by the

Editor's note: see related articles in this issue: doi:10.1007/s00247008-1084-6 and doi:10.1007/s00247-008-1137-x.

\footnotetext{
T. L. Slovis $(\bowtie)$

Department of Pediatric Imaging,

Children's Hospital of Michigan,

3901 Beaubien Blvd.,

Detroit, MI 48201, USA

e-mail: pedradeditor@med.wayne.edu

\section{S. Chapman}

Radiology Department,

Birmingham Children's Hospital NHS Foundation Trust,

Steelhouse Lane,

Birmingham B4 6NH, UK
}

same lead author [2] formed the basis of what became known as the "Geddes hypothesis" or "unified hypothesis." A further publication expanded on the original work [3]. On the basis of a pathologic study of 50 intrauterine, neonatal or infant deaths, in which microscopic intradural hemorrhage was identified in 36 , and dural surface hemorrhage, which was noted in 11, these authors speculated that subdural and retinal hemorrhages resulted from a combination of cerebral hypoxia, raised intracranial pressure from brain swelling, raised arterial pressure, and raised venous pressure. The original hypothesis was not well received by many involved in this field of pediatrics and generated public criticism [4], but was sufficiently credible to cause several criminal convictions to be reviewed by the Court of Appeal in the UK [5]. However, in the judgment, their Lordships stated "In our view ... cases of serious injuries caused by very minor force such as might occur in normal handling or rough handling of an infant, are likely to be rare or even extremely rare." [6]. We repeat, the vast majority of subdural hematomas in infants without adequate historical verification to explain the etiology are caused by NAT-child abuse.

It is important to note that there are legitimate reservations raised by some about the theories expressed in this article. These include:

1. The dura is dense fibrocollagenous tissue, and it is hard to imagine that blood can leak through it.

2. It is difficult to extrapolate from microscopic intradural and surface subdural hemorrhage to macroscopic subdural hemorrhage.

3. Many of the predisposing lesions in which "nontraumatic" subdural hematomas may occur (benign extraaxial collections, glutaric aciduria type 1) are associated with stretching of the bridging veins because of the extraaxial fluid collections. In these instances, 
minor trauma has been thought by many to cause the subdural hemorrhage.

4. The separation between the dura and the arachnoid is not an artifact and there is, indeed, a potential space between the two. When there is a subdural fluid/blood collection, the potential space becomes actual. There is no connection between the dura and arachnoid covering most of the brain and spinal cord. They are connected near the sinuses but, otherwise, the integrity of the dura and the arachnoid is not disturbed when the brain/spinal cord is/are removed. If they were attached, the arachnoid would be torn consistently, as it is the more delicate of the membranes.

At the end of the day, the article of Mack et al. makes us revisit the pathophysiology of subdural collections and subdural hematomas based on anatomy. It is an important article, but it does not provide insight into the inciting cause. Insight into the causative mechanism not only involves a meticulous medical history, a thorough physical and radiologic examination, and investigations into the various diseases that have been associated with these findings, but also additional investigations by other responsible authorities.

\section{References}

1. Mack J, Squier W, Eastman JT (2009) Anatomy and development of the meninges: implications for subdural collections and CSF circulation. Pediatr Radiol 39. doi:10.1007/s00247-008-1084-6

2. Geddes JF, Tasker RC, Hackshaw AK et al (2003) Dural haemorrhage in non-traumatic infant deaths: does it explain the bleeding in 'shaken baby syndrome'? Neuropathol Appl Neurobiol 29:14-22

3. Geddes JF, Whitwell HL (2004) Inflicted head injury in infants. Forensic Sci Int 146:83-88

4. Punt J, Bonshek RE, Jaspan T et al (2004) The 'unified hypothesis' of Geddes et al. is not supported by the data. Pediatr Rehabil 7:173-184

5. Richards PG, Bertocci GE, Bonshek RE et al (2006) Shaken baby syndrome. Arch Dis Child 91:205-206

6. Supreme Court of Judicature, Court of Appeal (Criminal Division). Neutral Citation Number [2005] EWCA Crim 1980. Case Nos: 200403277, 200406902, 200405573, 200302848. Approved Judgment. Paras 78, 79. Royal Courts of Justice, London 